\title{
Roselle (Hibiscus sabdiriffa) Polyphenol-Rich Extract Prevents Testicular Damage of Diabetic Rats
}

Siti Balkis Budin, Wan Zafirah Abdul Rahman, Fatin Farhana Jubaidi, Nur Liyana Mohammed Yusof, Izatus Shima Taib, Satirah Zainalabidin

Biomedical Science Programme, Faculty of Health Sciences, Universiti Kebangsaan Malaysia, Jalan Raja Muda Abdul Aziz, 50300 Kuala Lumpur, Malaysia.

\section{ARTICLE INFO \\ Article history: \\ Received on: 31/10/2017 \\ Accepted on: 16/01/2018 \\ Available online: 27/02/2018}

\section{Key words:}

Diabetes mellitus Type 1, roselle, male reproductive organs, oxidative stress.

\begin{abstract}
Oxidative stress plays a critical role in diabetes-induced complications including injurious effect on male reproductive organ. Hibiscus sabdariffa Linn. or roselle possesses antioxidant properties and widely used to treat various diseases. The study was aimed to evaluate the effect of $H$. sabdariffa polyphenol-rich extract (HPE) from the calyces towards male reproductive organs in diabetic rats. Twenty-four male rats were divided into three groups; (i) normal nondiabetic (NDM), (ii) diabetic (DM) and (iii) diabetic treated with HPE (DM + HPE) groups. Diabetes was induced with streptozotocin $(60 \mathrm{mg} / \mathrm{kg}$, single i.p.). HPE $(100 \mathrm{mg} / \mathrm{kg})$ was administrated by forced feeding for 28 consecutive days before being sacrificed to harvest their reproductive organs. Results showed that superoxide dismutase (SOD) and catalase (CAT) activities as well as gluthathione (GSH) levels in the testis homogenate of DM + HPE group were significantly higher $(\mathrm{p}<0.05)$ compared to DM group. Meanwhile, significantly lower levels of malondialdehyde (MDA) and protein carbonyl (PC) were observed in DM + HPE group compared to DM group. The histological observation showed morphological alteration of the testis in DM group, which was impeded following supplementation of HPE. In conclusion, this suggests that HPE supplementation is able to prevent oxidant injury of testis of diabetic rats.
\end{abstract}

\section{INTRODUCTION}

Diabetes mellitus is a chronic progressive disease, mainly featured by high blood glucose level. It is a common metabolic disease and affects millions of patients worldwide and the prevalence is rapidly rising in developing countries (Rajiv et al., 2014). This ailment is originated from the failure of insulin secretion due to $\beta$ cells destruction in the pancreas or the insulin resistance of the peripheral tissues due to prolonged over-exposure of insulin (Goycheva et al., 2006). Prolonged hyperglycemia causes the disturbance of carbohydrate, protein and lipid metabolism, which would cause free radicals overproduction through various metabolic pathways, leading to intracellular oxidative stress.

Tissue damage exerted by free radicals activity is an important factor in the pathogenesis of DM complications,

${ }^{*}$ Corresponding Author

Siti Balkis Budin, Biomedical Science Programme, Faculty of Health

Sciences, Universiti Kebangsaan Malaysia, Jalan Raja Muda Abdul

Aziz, 50300 Kuala Lumpur, Malaysia.E-mail: balkis@ukm.edu.my displayed by marked elevation of oxidative stress markers including high levels of malondialdehyde (MDA) and protein carbonyl (PC) as well as alteration in antioxidants status (Murali et al., 2013), Testis is composed of high polyunsaturated fatty acid and possesses scanty antioxidants reserve for its defense thus making it highly vulnerable to free radicals attack. Being the organ that produces the sperm and taking parts in regulating the reproductive hormones, testis is a key organ for reproductive events. Studies reported that diabetic condition caused testicular dysfunctions including alterations of reproductive hormone, disturbances in spermatogenesis and reduction of sperm qualities, which all directly related to the testicular health (Agarwal et al., 2012; Aitken et al., 2014).

It has been postulated that the balance between oxidant and antioxidant caters an important role in preventing the pathogenesis of diabetic complications. A wide array of natural products has been found to be endowed with the ability to control oxidative stress and metabolic disorders in diabetic conditions. Hibiscus sabdariffa Linn., also known as roselle, was reported 
to have strong antioxidant properties mainly due to the abundant content of polyphenolic compounds, including anthocyanin, phenolic acids, flavonoids and many others (Lin et al., 2012; Lim et al., 2016). Roselle calyx extract possesses antihypertensive, hypolipidemic and hepatoprotective properties (Puro et al., 2014; Si et al., 2017). Protocatechuic acid known to be present in roselle acts as a potent antioxidant and has a potential in preventing the development of diabetes-related pathologies (Farombi and Ige, 2007).

Polyphenols are compounds possessing aromatic rings with hydroxyl group, making it a potent antioxidant (Dai and Mumper, 2010). As antioxidants, polyphenols may protect cell constituents against oxidative damage and therefore, limit the risk of various degenerative diseases associated to oxidative stress (Scalbert et al., 2005). Polypenol-rich extract derived from roselle (HPE) was specifically reported to be able to improve the state of oxidative stress significantly in diabetic kidney and heart (Lee et al., 2009; Lim et al., 2017).

Recent studies reported that aqueous extract of dried roselle calyx has a potential in protecting against diabetic-induced sperm damage (Md Idris et al., 2012). However, HPE's beneficial effects on the reproductive organs in hyperglycemic condition has not been fully investigated yet. In diabetic condition the functional impairment of the testes might be resulted from oxidative stress ( $\mathrm{La}$ Vignera et al., 2012). Therefore, our study aim is to evaluate the potential of HPE in preventing testicular damage in diabetic rats.

\section{MATERIALS AND METHODS}

\section{Extraction of roselle polyphenols}

Dried roselle UKMR-1 calyces (Specimen Voucher No. UKM 40308) was supplied by Ai Agro Marketing, Terengganu, Malaysia. HPE was prepared as described by Peng et al. (2011). Five grams of dried UKMR-1 roselle calyxes were extracted with methanol and stirred for 30 minutes in a water bath at $60^{\circ} \mathrm{C}$. The extracts were filtered and concentrated using rotary evaporator $\left(\leq 5^{\circ} \mathrm{C}, 20 \mathrm{mbar}\right)$. The dried residue was then solubilized in deionized water at $\mathrm{pH}$ 2.3. The aqueous solution then re-extracted with hexane followed by ethyl acetate. The ethyl acetate soluble fraction was evaporated to dry. The final product of dried crude $\mathrm{HPE}$ was stored at $-40^{\circ} \mathrm{C}$ for further use.

\section{Experimental design and dosing schedule}

Twenty-four male Sprague-Dawley rats weighing between 250-300 $\mathrm{g}$ each were obtained from the Animal Unit, Faculty of Medicine, Universiti Kebangsaan Malaysia. All animals were maintained on a balanced diet and water ad libitum without restriction, and were kept two rats per cage. The rats were randomized into three groups comprising of 8 animals each: (i) normal non-diabetic (NDM), (ii) diabetic (DM) and (iii) diabetic treated with HPE (DM + HPE). Type I diabetes was induced by a single intraperitoneal injection of streptozotocin (Sigma, USA) at the dose of $60 \mathrm{mg} / \mathrm{kg}$ body weight after an overnight fasting (Bagri et al., 2009). Blood glucose level was measured 72 hours after diabetes induction where rats with blood glucose levels above 15 $\mathrm{mmol} / \mathrm{L}$ were included in this study. NDM group and DM group received normal saline whereby DM + HPE group received HPE at the dose $100 \mathrm{mg} / \mathrm{kg}$ body weight (Peng et al., 2011) daily for 28 consecutive days. The study design has been approved by Universiti Kebangsaan Malaysia Animal Ethics Committee Animal Ethics Committee (Ethical No: FSK/2015/BALKIS/11-FEB./643-FEB.2015-FEB.-2018).

\section{Sample collection}

At the end of study period, all rats were fasted overnight and blood specimen was collected via cardiac puncture under deep anesthesia. Testes were excised from sacrificed rats and weighed. One of the testes was stored in $-40^{\circ} \mathrm{C}$ for homogenate preparation for oxidative stress study while the other was fixed in $10 \%$ formalin for histological analysis.

\section{Homogenate preparation}

The testis was washed with normal saline before the capsule was removed to obtain the seminiferous tubule, which were then minced using a scalpel. After being weighed, the testis was then homogenized in phosphate buffer solution at $\mathrm{pH}$ 7.8. After centrifugation (13000 rpm), the supernatant was removed and stored at $-40^{\circ} \mathrm{C}$. The whole procedure was conducted in cold condition. This homogenate was used for oxidative stress evaluation.

\section{Assessment of oxidative stress biomarkers}

The level oflipid peroxidation was estimated by measuring the level of thiobarbituric reactive species (TBARS) as described by Stock and Dormandy (1971). 2,4-dinitrophenylhydrazin (DNPH) reaction in the sample was measured to estimate the level of protein carbonyl (PC) as demonstrated by Levine et al. (1990). The level of superoxide dismutase (SOD) activity was estimated by using assay method by Beyer and Fridovich (1987). Reduced glutathione (GSH) level was measured according to Ellman (1959) and catalase activity was measured according to the method by Aebi (1984).

\section{Histopathological studies}

A portion of autopsied testis was washed in normal saline and fixed in $10 \%$ formalin solution. The tissues then dehydrated in alcohol series of ascending concentration, cleared in xylene before being embedded in paraffin to form blocks of tissues. Sections of the tissues of 3-4 $\mu$ m thick were obtained using microtome then deparaffinized. The tissue sections were then stained with hematoxylin and eosin for histological observation under light microscope (Bancroft and Gamble 2002).

\section{Statistical analysis}

The data were analysed using GraphPad Prism software (GraphPad Software 6.0, San Diego) and expressed as mean \pm standard error of mean (SEM). Statistical significance was determined by one-way ANOVA followed by Post Hoc Tukey's test and $p$-value $<0.05$ was considered statistically signicant difference.

\section{RESULTS AND DISCUSSION}

\section{Fasting blood glucose levels}

Table 1 shows the fasting blood glucose levels of all experimental groups. DM and DM + HPE groups showed significant rise in fasting blood glucose $(\mathrm{FBG})$ level $(\mathrm{p}<0.05)$ 
when compared with NDM. However, the FBG level of DM + HPE group was significantly lower than DM group $(\mathrm{p}<0.05)$.

In the present study, normal rats were administered with STZ to induce type I diabetes mellitus. High level of blood glucose in STZ-induced rats was observed when compared to normal rats. Disturbance in glucose homeostasis is owed to STZ-induced damage on pancreatic $\beta$ cells, causing insufficiency of insulin secretion (Mohamed et al., 2012; Budin et al., 2013). Diabetic rats showed significant decrease in blood glucose level upon treatment with HPE. The improvement of blood glucose level might be due to the protective effect exerted by the antioxidant properties in HPE resulting in prevention of further destruction of $\beta$ cells by antioxidant mechanism (Peng et al., 2011). Previous study had found that the use of tocotrienol-rich fraction, a potent antioxidant, was able to reduce the damage of pancreatic $\beta$ cells and improve the blood glucose in diabetic rats (Budin et al., 2011). Polyphenols are also functioning by increasing glucose uptake and causes up-regulation of glucose transporter in skeletal muscle, thus lowering the blood glucose level in diabetic rats (Kim et al., 2016).

Table 1: Fasting blood glucose level.

\begin{tabular}{lccc}
\hline Group & NDM & DM & DM + HPE \\
\hline FBG $(\mathrm{mmol} / \mathrm{L})$ & $4.28 \pm 0.553$ & $32.23 \pm 1.840^{\mathrm{a}}$ & $23.06 \pm 2.920^{\mathrm{a}, \mathrm{b}}$ \\
\hline
\end{tabular}

(A)

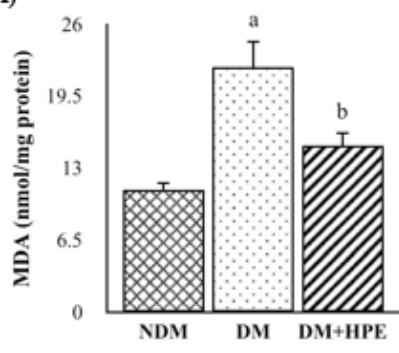

(C)

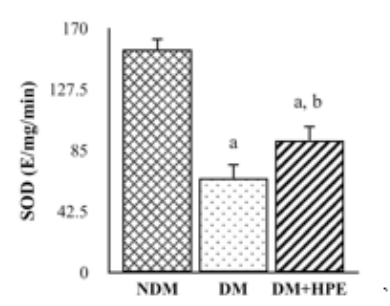

Values are expressed as mean \pm SEM where mean significant at $\mathrm{p}<0.05$.

${ }^{a}$ compared with NDM group; ${ }^{b}$ compared with DM group.

Table 2: Body and organ weights.

\begin{tabular}{lccc}
\hline Groups & NDM & DM & DM + HPE \\
\hline \multicolumn{4}{c}{ Body weight $(\mathrm{g})$} \\
\hline Initial & $265.3 \pm 3.7$ & $250.4 \pm 1.6^{\mathrm{a}}$ & $254.5 \pm 1.7^{\mathrm{a}, \mathrm{b}}$ \\
Final & $353.4 \pm 5.4$ & $171.1 \pm 2.6^{\mathrm{a}}$ & $266.6 \pm 12.2^{\mathrm{a}, \mathrm{b}}$ \\
\hline \multicolumn{4}{c}{ Absolute weight of reproductive organs $(\mathrm{g})$} \\
\hline Testis & $1.30 \pm 0.04$ & $0.40 \pm 0.04^{\mathrm{a}}$ & $0.99 \pm 0.14^{\mathrm{a}, \mathrm{b}}$ \\
Prostate & $0.57 \pm 0.02$ & $0.27 \pm 0.02^{\mathrm{a}}$ & $0.38 \pm 0.04^{\mathrm{a}}$ \\
Seminal vesicle & $0.63 \pm 0.15$ & $0.30 \pm 0.04^{\mathrm{a}}$ & $1.38 \pm 0.08^{\mathrm{a}}$ \\
\hline
\end{tabular}

Values are expressed as mean \pm SEM where mean significant at $\mathrm{p}<0.05$ ${ }^{a}$ compared with NDM group; ${ }^{b}$ compared with DM group.

\section{Body and reproductive organs weights}

The initial and final body weights of all experimental groups are shown in Table 2. The reduction of body weight in diabetic rats is obviously seen in both diabetic groups. In diabetic condition, because of insulin deficiency, peripheral cells are unable to use glucose as energy source. Body weight progressively reduced due to energy source being rerouted from glucose metabolism to fat and muscle from the process of lipolysis and proteolysis respectively.

(B)

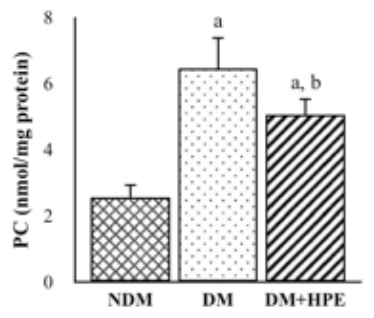

(D)
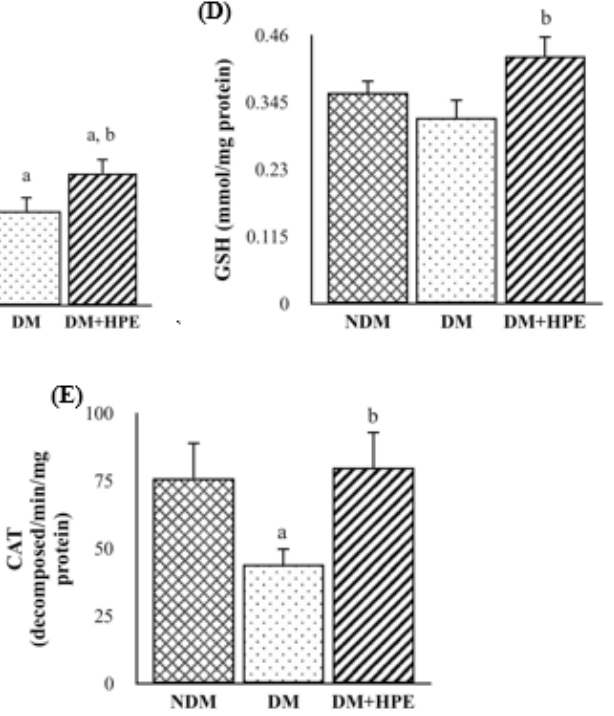

Figure 1: Effects of HPE treatment on the levels of (A) Malondialdehyde (MDA) and (B) Protein carbonyl (PC) as well as the status of (C) Superoxide dismutase (SOD), (D) Glutathione (GSH) and (E) Catalase (CAT) of testis.

Values are expressed as mean \pm SEM where mean significant at $\mathrm{p}<0.05$. ${ }^{\mathrm{a}}$ compared with NDM group; ${ }^{\mathrm{b}}$ compared with DM group.

Treatment of diabetic rats with HPE was potent in protecting against weight loss and instead helped the rats to gain 
weight. The improvement of body weight in DM + HPE group could be due to the amelioration of diabetic status as can be seen in the reduction in the blood glucose level. Improvement of body weight in diabetic rats by treatment of anti-diabetic plant extracts have been previously reported in past studies (Algariri et al., 2013; Pandhere et al., 2011).
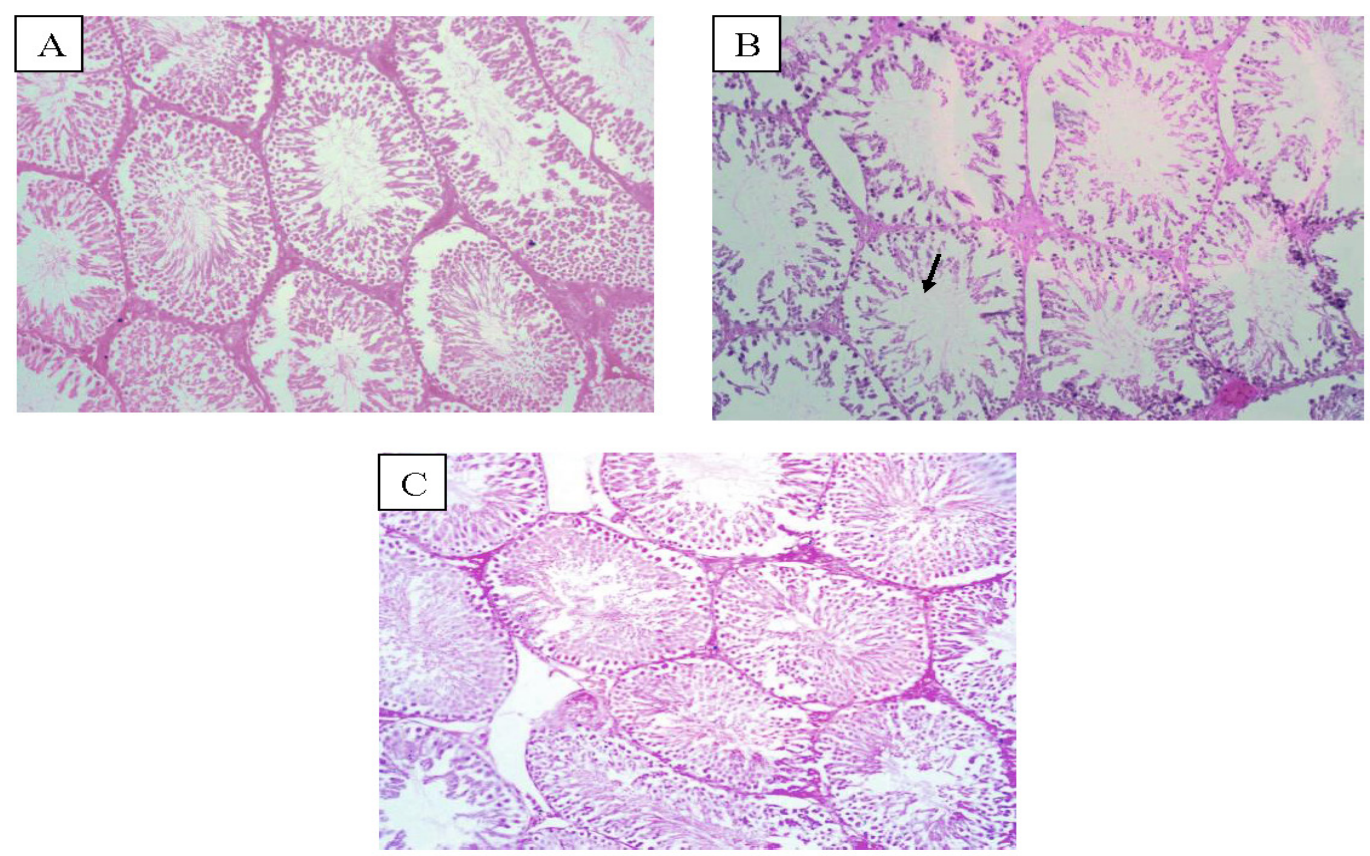

Figure 2: Testicular histology. (A) NDM group testis. Note germinal epithelium lining seminiferous tubules are well defined and the spermatogenic cells are seen in the tubules. (B) DM group testis. Note disrupted and thinned germinal epithelium, sloughing of spermatozoa from the lumens (arrows), decreased tubule diameter and increased in interstitial space between tubules. (C) DM + HPE group testis. Note the histology is comparable to NDM group. (H\&E) (X100).

The weights of testis, prostate and seminal vesicle of all groups at the end of the study are shown in Table 2 . The weights of all organs in DM group are significantly lower than NDM group. The weight of testes in DM + HPE group is significantly higher than DM group $(\mathrm{p}<0.005)$, whereas for prostate and seminal vesicle weight in DM + HPE group, both show increase in weight but no significant difference compared to DM group $(\mathrm{p}>0.05)$. Decreased in reproductive organs weight could also be a factor to the decreased of body weight in diabetic rats due to hormonal and metabolic changes in hyperglycemia state (Fernandes et al., 2011; Md Idris et al., 2012).

\section{Oxidative stress markers}

The etiology of oxidative stress in diabetic state originates from various mechanisms which includes overproduction of free radicals from glucose auto-oxidation and glycation of proteins. The alteration in antioxidative enzymes results in the limitation of their capacity to detoxify oxygen radicals (Matough et al., 2012). Oxidative stress biomarkers investigated in this study are MDA and PC which both were significantly higher in the testis of diabetic rats without treatment $(\mathrm{p}<0.05)$, indicating an increase of lipid peroxidation and protein oxidation. Similar findings also had been reported in previous studies pertaining similar diabetic models (Lee et al., 2009; Budin et al., 2013). Meanwhile, low levels of endogenous antioxidants, which is GSH, as well as reduced in CAT and SOD activities are manifested in diabetic rats without treatment compared to non-diabetic rats $(\mathrm{p}<0.05)$.

From this study, the level of MDA and PC were decreased significantly $(p<0.05)$ in diabetic rats treated with HPE, which supported the antioxidant properties of HPE. Polyphenol is the main source of human exogenous antioxidant and is naturally found in abundance in plants (Kim et al., 2016; Rocha et al., 2014). Previous studies reported that polyphenol are potent antioxidant and able to scavenge free radicals. Polyphenols also has an antihyperglycaemic activity, which may suppress glucose release from the liver as well as improving glucose uptake in peripheral tissues (Prabhakar and Dioble, 2009). The amelioration of blood glucose level in HPE-treated diabetic rats and the antioxidant property of HPE reduced the reactive oxygen species (ROS) generation and activities, subsequently reduces the lipid peroxidation and protein oxidation (Murali et al., 2011; Kim et al., 2016). In this study, diabetic rats treated with HPE shown the improvement in the antioxidant status as the levels of GSH, as well as CAT and SOD activities well as SOD activity were increased significantly $(\mathrm{p}<0.05)$. The improvement in endogenous antioxidants status most probably due to low levels of ROS generation and also the capacity of polyphenol to scavenge free radicals that cause reduction antioxidant consumption (Lim et al., 2016).

\section{Histopathological studies of testis}

Histology studies of testis showed that in the NDM group, seminiferous tubules appearance, spermatogenic cells density and thickness of basement membrane appeared normal (Figure 2A). 
On the other hand, there were obvious morphological changes in the testis of diabetic rats. The size of the seminiferous tubule was smaller whereas the interstitial space between the tubules was larger. There were also less spermatids seen in the tubules and atrophy of seminiferous tubules was also observed (Figure 2B). In the DM + HPE group, morphological changes due to diabetes was not observed. The appearance of all tubules was normal and all the spermatogenic cells were normally visible (Figure 2C).

Prolonged and constant exposure to free radicals in diabetic state leads to destruction of testicular tissue (Giacco and Brownlee, 2010; Ding et al., 2015). The testicular tissue is highly vulnerable to oxidative damage contributed by the abundance of polyunsaturated fatty acid (PUFA) content in its structure (Giacco and Brownlee, 2010). The present finding showed that administration of HPE to diabetic rats could reverse this effect. The protective effects of this extract may be due to its free radical scavenging properties, which leads to the reduction in the oxidative damage of testis.

\section{CONCLUSION}

We concluded that HPE was able to protect against oxidant damage to the testis in diabetic condition by possibly inhibiting the oxidative stress through its anti-hyperglycemic and antioxidant activities.

\section{ACKNOWLEDGMENT}

The authors would like to thank the Ministry of Education of Malaysia (MOE) for supporting the research project (FRGS/2/2014/SG03/UKM/02/2).

\section{CONFLICT OF INTERESTS}

There are no conflicts of interest.

\section{REFERENCES}

126.

Aebi H. Catalase in vitro. Methods Enzymol, 1984; 105: 121-

Agarwal A, Aponte-Mellado A, Premkumar BJ, Shaman A, Gupta S. The effects of oxidative stress on female reproduction: a review. Reprod Biol Endocrinol, 2012; 10: 49-80.

Aitken RJ, Smith TB, Jobling MS, Baker MA, De Iuliis GN. Oxidative stress and male reproductive health. Asian J Androl, 2014; 16(1): 31-38.

Algariri K, Meng KY, Atangwho IJ, Asmawi MZ, Sadikun A, Murugaiyah V, Ismail N. Hypoglycemic and anti-hyperglucemix study of Gynura procumbens leaf extracts. Asian Pac J Trop Biomed, 2013; 3(5): 358-366.

Bagri P, Ali M, Aeri V, Bhowmik M, Sultana S. Antidiabetic effect of Punica granatum flowers: effect on hyperlipidemia, pancreatic cells lipid peroxidation and antioxidant enzymes in experimental diabetes. Food Chem Toxicol, 2009; 47(1): 50-54.

Bancroft JD, Gamble M. Theory and practice of histological techniques. 5th ed. Edinburgh: Churchill Livingstone Pub., 2002; 172.

Beyer WF, Fridovich I. Assaying for superoxide dismutase activity: some large consequences of minor changes in conditions. Anal Biochem, 1987; 161(2): 559-566.

Budin SB, Yusof KM, Idris MHM, Hamid ZA, Mohamed J. Tocotrienol-rich fraction of palm oil reduced pancreatic damage and oxidative stress in streptozotocin-induced diabetic rats. Aust J Basic Appl Sci, 2011; 5(12): 2367-2374.

Budin SB, Ismail H, Chong PL. Psidium guajava fruit peel extract reduces oxidative stress of pancreas in streptozotocin-induced diabetic rats. Sains Malays, 2013; 42(6): 707-713.

Dai J, Mumper RJ. Plant phenolics: extraction, analysis and their antioxidant and anticancer properties. Molecules, 2010; 15(10): 7313-7352.

Ding GL, Liu Y, Liu ME, Pan JX, Guo MX, Sheng JZ, Huang HF. The effects of diabetes on male fertility and epigenetic regulation during spermatogenesis. Asian J Androl 2015; 17(6): 948.

Ellman GL. Tissue sulfhydryl groups. Arch Biochem Biophys, 1959. 82(1): 70-77.

Farombi EO, Ige OO. Hypolipidemic and antioxidant effects of ethanolic extract from dried calyx of Hibiscus sabdariffa in alloxan-induced diabetes rats. Fundam Clin Pharmacol, 2007; 21(6): 601-609.

Fernandes GS, Fernandez CD, Campos KE, Damasceno DC, Anselmo-Franci JA, Kempinas WD. Vitamin C partially attenuates male reproductive deficits in hyperglycemic rats. Reprod Biol Endocrinol, 2011; 9(1): 100 .

Giacco F, Brownlee M. Oxidative stress and diabetic complications. Circ Res, 2010; 107(9): 1058-1070.

Goycheva P, Gadjeva V, Popov B. Mini-review Oxidative Stress And Its Complications In Diabetes. Trakia J Sci, 2006; 4(1): 1-8.

Jain GC, Jangir RN. Modulation of diabetes-mellitus-induced male reproductive dysfunctions in experimental animal models with medicinal plants. Pharmacogn Rev, 2014; 8(16): 113-121.

Kim Y, Keogh JB, Clifton PM. Polyphenols and Glycemic Control. Nutrients, 2016; 8(1): 17.

La Vignera S, Condorelli R, Vicari E, D'Agata R, Calogero AE Diabetes Mellitus and Sperm Parameters. J Androl, 2012; 33(3): 145-153.

Lee WC, Wang CJ, Chen YH, Hsu JD, Cheng SY, Chen HC, Lee HJ. Polyphenol extracts from Hibiscus sabdariffa Linnaeus attenuate nephropathy in experimental type 1 diabetes. J Agric Food Chem, 2009; 57(6): 2206-2210.

Levine RL, Garland D, Oliver CN, Amici A, Climent I, Lenz AG, Stadtman ER. Determination of carbonyl content in oxidatively modified proteins. Methods, Enzymol, 1990; 186: 464-78.

Lim YC, Budin SB, Othman F, Latip J, Zainalabidin S. Roselle Polyphenols Exert Potent Negative Inotropic Effects via Modulation of Intracellular Calcium Regulatory Channels in Isolated Rat Heart. Cardiovasc Toxicol, 2017; 17(3): 251-159.

Lin HH, Chan KC, Sheu JY, Hsuan SW, Wang CJ, Chen JH. Hibiscus sabdariffa leaf induces apoptosis of human prostate cancer cells in vitro and in vivo. Food Chem, 2012; 132(2): 880-891.

Matough FA, Budin SB, Abdul Hamid Z, Alwahaibi N, Mohamed $\mathrm{J}$. The role of oxidative stress and antioxidants in diabetic complications Sultan Qaboos Univ Med J, 2012; 12(1): 5.

Md Idris MH, Budin SB, Mohamed J, Osman M. Protective role of Hibiscus sabdariffa calyx extract against streptozotocin induced sperm damage in diabetic rats. EXCLI J, 2012; 11: 659-669.

Mohamed J, Mohd Nor NA, Budin SB. Effect of Aqueous Extract of Roselle Calyx (Hibiscus sabdariffa Linn) on Hidrogen Peroxide Induced Oxidative Stress of Rat Red Blood Cell Membranes. Int J Collab Res Intern Med Public Health, 2012; 4(12): 2111- 2127.

Murali R, Karthikeyan A, Saravanan R. Protective Effects of d-Limonene on Lipid Peroxidation and Antioxidant Enzymes in Streptozotocin-Induced Diabetic Rats. Basic Clin Pharmacol Toxicol, 2013; 112(3): 175-181.

Pandhere RS, Dambay A, Sangameswaran B, Mohite PB, Khanage SG. Antidiabetic activity of aqueous leaves extract of Sesbania sesban (L) Merr. in streptozotocin induced diabetic rats. Avicenna J Med Biotechnol, 2011; 3(1): 37-43.

Peng CH, Chyau CC, Chan KC, Chan TH, Wang CJ, Huang CN.. Hibiscus sabdariffa polyphenolic extract inhibits hyperglycemia, hyperlipidemia, and glycation-oxidative stress while improving insulin resistance. J Agric Food Chem, 2011; 59(18): 9901-9909.

Prabhakar PK, Doble M. Synergistic effect of phytochemicals in combination with hypoglycemic drugs on glucose uptake in myotubes. Phytomed, 2009; 16: 1119-1126. 
Puro K, Sunjukta R, Samir S, Ghatak S, Shakuntala I, Sen A. Medicinal Uses of Roselle Plant (Hibiscus sabdariffa L.): A Mini Review. Indian J Hill Fmg, 2014; 27(1): 81-90.

Rocha IDC, Bonnlaender B, Sievers H, Pischel I, Heinrich M. Hibiscus sabdariffa L. A phytochemical and pharmacological review. Food Chem, 2014; 165:424-443.

Scalbert A, Manach C, Morand C, Rémésy C, Jiménez L. Dietary polyphenols and the prevention of diseases. Cric Rev Food Sci Nutr, 2005; 45(4): 287-306.

Si LYN, Ali SAM, Latip J, Fauzi NM, Budin SB, Zainalabidin $\mathrm{S}$. Roselle is cardioprotective in diet-induced obesity rat model with myocardial infarction. Life Sci, 2017; 191: 157-165.
Stocks J, Dormandy TL. The autooxidation of human red cell lipids induced by hydrogen peroxide. J Hematol, 1971; 20(1): 95-111.

\section{How to cite this article:}

Budin SB, Abdul Rahman WZ, Jubaidi FF, Mohammed Yusof NL, Taib IS, Zainalabidin S. Roselle (Hibiscus sabdiriffa) Polyphenol-Rich Extract Prevents Testicular Damage of Diabetic Rats. J App Pharm Sci, 2018; 8(02): 065-070. 